\title{
Distant effects of unilateral renal ischemia/reperfusion on contralateral kidney but not lung in rats: the roles of ROS and iNOS
}

\begin{tabular}{|r|l|}
\hline Journal: & Canadian Journal of Physiology and Pharmacology \\
\hline Manuscript ID & cjpp-2015-0285.R2 \\
\hline Manuscript Type: & Article \\
\hline Date Submitted by the Author: & 08-Oct-2015 \\
\hline Complete List of Authors: & $\begin{array}{l}\text { Fatemikia, Hossein; Shiraz University of Medical Sciences, Physiology } \\
\text { Ketabchi, Farzaneh; Shiraz University of Medical Sciences, Physiology } \\
\text { Karimi, Zynab; Shiraz University of Medical Sciences, Physiology } \\
\text { Moosavi, S.; Shiraz University of Medical Sciences, Physiology }\end{array}$ \\
\hline Keyword: & $\begin{array}{l}\text { Acute kidney injury, inducible nitric oxide synthase, reactive oxygen } \\
\text { species, unilateral nephrectomy, unilateral renal ischemia }\end{array}$ \\
\hline \multicolumn{2}{|c}{} \\
\hline
\end{tabular}

\section{SCHOLARONE" \\ Manuscripts}




\section{Distant effects of unilateral renal ischemia/reperfusion on contralateral kidney but not lung in rats: the roles of ROS and iNOS}

Hossein Fatemikia, Farzaneh Ketabchi, Zynab Karimi and Seyed Mostafa Shid Moosavi

Department of Physiology, The Medical School, Shiraz University of Medical Sciences, Shiraz 71365-1689, Iran.

Author for Correspondence: Dr Seyed Mostafa Shid Moosavi, Department of Physiology, The Medical School, Shiraz University of Medical Sciences, Shiraz 713651689, Iran. Phone and Fax: 0098-71-32302026 Email: 


\begin{abstract}
Acute kidney injury is usually associated with distant organ dysfunction. The roles of inducible nitric oxide synthase (iNOS) and reactive oxygen species (ROS) in this phenomenon were investigated following 2-h unilateral renal ischemia and 24-h reperfusion. There were three groups of rats subjected to either unilateral ischemia/reperfusion (UIR group), unilateral nephrectomy (UNX group), or shamoperation. Two further groups were given $\alpha$-tocopherol and aminoguanidine with UIR (treated-UIR group) and UNX (treated-UNX group). Plasma nitrite/nitrate and malondialdehyde were elevated only in the UIR group. Creatinine clearance and blood flow increased in non-ischemic kidney of the UIR, but not to the same extent as remnant kidney of the UNX group, while they had equal compensatory rises in absolute $\mathrm{Na}^{+}$- and $\mathrm{K}^{+}$-excretion and urine flow. Non-ischemic kidney of the treated-UIR group, but not remnant kidney of the treated-UNX group, showed more elevation in blood flow, whereas both kidneys had reductions in absolute $\mathrm{Na}^{+}$-excretion and urine flow. Respiratory functional variable were not different between all groups. Therefore, 2-h unilateral renal ischemia and 24-h reperfusion did not affect lung but had distant effects on contralateral kidney partly mediated by ROS and NO-derived from iNOS to dampen compensatory increases in renal hemodynamics and to decrease tubular reabsorption.
\end{abstract}

Keywords: Acute kidney injury, acute lung injury, alpha-tocopherol, aminoguanidine, inducible nitric oxide synthase, ischemia/reperfusion, reactive oxygen species, unilateral nephrectomy, unilateral renal ischemia. 


\section{Introduction}

Acute kidney injury (AKI) comprises $30-50 \%$ of admissions to critical care units. Despite advances in the renal replacement therapies and intensive care support, patients with AKI still have mortality rates of more than 50\% (Awad and Okusa 2007; Sharfuddin et al. 2012). In addition, AKI rarely occurs in isolation and is frequently associated with multi-organ dysfunction. Of particular note, patients with AKI have a high incidence of acute lung injury (ALI) in the intensive care setting, which elevates the mortality rate to about $80 \%$ (Awad and Okusa 2007; Ko et al. 2009). The pulmonary circulation, which receives all cardiac output, responds to circulating factors released from other injured organs, with a resultant ALI (Ko et al. 2009). There are several studies on rodents that demonstrate reactive oxygen species (ROS) and inducible nitric oxide synthase (iNOS) play roles in the induction of ALI following ischemia/reperfusion (IR) injury in the hind limb (Punch et al. 1991), intestine (Zhou et al. 2003) and kidney (Campanholle et al. 2010), as well as rhabdomyolysis-induced AKI (Rodrigo et al. 2006).

It should be noted that AKI may affect distant organs not only via releasing injurious mediators but also via impairing clearance of pro-inflammatory cytokines as well as inducing systemic uremia (Faubel 2008; Ko et al. 2009). In this regard, different models of AKI have been developed to cause renal ischemia with uremia (bilateral renal ischemia/reperfusion; BIR), renal ischemia without uremia (unilateral renal ischemia/reperfusion; UIR), and uremia without renal ischemia (bilateral nephrectomy; BNX) (Hoke et al. 2007; Rabb et al. 2003). Multiple investigators demonstrated that BNX and BIR in rodents induced similar lung injury (Hoke et al. 2007; Kim et al. 2006; Klein et al. 2008; Rabb et al. 2003). In addition, Hoke et al. (2007) showed that BIR and 
BNX elevated multiple serum cytokines but with different profiles. However, 22-min ischemia and 24-h reperfusion (Hoke et al. 2007) or 30-min ischemia and 48-h reperfusion (Rabb et al. 2003) in the UIR model did not affect plasma cytokines, creatinine and urea as well as lungs. This was possibly because the degree of ischemia was insufficient to induce appreciable changes or alternatively, there was compensation by the normally functioning contralateral kidney. This view was supported by the observations that unilateral renal ischemia with longer durations of $40 \mathrm{~min}$ in rats (Barrilli et al. 2004) and $45 \mathrm{~min}$ in mice (Miyazama et al. 2002) resulted in increased BUN after $24 \mathrm{~h}$ and $3 \mathrm{~h}$ of reperfusion, respectively, which in the latter study was associated with the increased accumulation of neutrophils and intermediate T-cells in both kidneys, spleen and liver, along with hepatic dysfunction. Other studies also showed that $60 \mathrm{~min}$ of unilateral renal ischemia in rodents caused elevation of inflammatory molecules and neutrophil or macrophage infiltration in both ischemic and non-ischemic kidneys (Meldrum et al. 2002; Tokuyama et al. 2007). Therefore, sufficient prolong ischemia in the UIR model could induce distant organ injury, including the contralateral non-ischemic kidney (NIK) with limiting the development of its full compensatory function. However, the remnant kidney in the unilateral nephrectomy (UNX) model normally exhibited complete compensatory hypertrophy and overfunction to maintain homeostasis of waste products, solutes and water (Aytac et al. 2008; Ni et al. 1998). Of note, the previous studies concerning distant effects of ischemic kidney in the UIR model focused on histopathological and inflammatory changes in other organs and measured plasma urea and creatinine as the indicators of renal function. Therefore, in the present study, a 2-h unilateral renal ischemia was chosen to very severely and nearly completely disturb post-ischemic kidney (POK) 
function in order to investigate its distant effect on hemodynamics, solutes excretion and urine concentrating ability of the contralateral kidney after 24-h reperfusion. This was done by comparing the compensatory function of the contralateral NIK with that of the remnant kidney at $24 \mathrm{~h}$ after performing UNX. In addition, the effects of UIR and UNX on pulmonary vascular permeability and lung function were investigated. Finally, the combined role of ROS and iNOS in responses of lungs and kidneys in the UIR and UNX models were determined by co-administration of $\alpha$-tocopherol, as a potent antioxidant, and aminoguanidine, as an iNOS inhibitor. Of course, the separate roles of ROS and iNOS in these situations will be investigated in a future study. 


\section{Materials and Methods}

\section{Experimental animals and groups}

This study was performed on 75 male Sprague-Dawley rats weighing 280-320 g, which were kept in cages at a temperature-controlled room $\left(23 \pm 1{ }^{\circ} \mathrm{C}\right)$ with $12 \mathrm{~h}$ artificial light and dark cycle. The rats were fed standard rodent diet with free access to water. All procedures conformed to the guidelines for the care and handling of animals prepared by the Ethics Committee of Shiraz University of Medical Sciences and in accordance with the international conventions on animal experimentation.

The rats were divided into 5 groups of $n=15$. There was no treatment in 3 groups of rats subjected to either unilateral renal ischemia/reperfusion (UIR group), unilateral nephrectomy (UNX group), or sham-operation (sham group). Two further groups of rats were co-treated with $\alpha$-tocopherol and aminoguanidine (dosages based on our previous studies) and subjected to either UIR (treated-UIR group) or UNX (treated-UNX group). $\alpha$-tocopherol acetate (Sigma, Poole, Dorset, UK), as the most potent lipid-soluble antioxidant, was intraperitoneally (i.p.) injected at $50 \mathrm{mg} \mathrm{kg}^{-1}$ at $6 \mathrm{~h}$ before and $9 \mathrm{~h}$ after unilateral renal ischemia or nephrectomy (Moosavi et al. 2010; Moosavi et al. 2011). Aminoguanidine hemisulfate (Molekula, Shaftesbury, Dorset, UK), a selective inhibitor of iNOS, was used at a dosage without affecting eNOS or nNOS (Moosavi et al. 2013). It was intravenously infused at $20 \mathrm{mg} \mathrm{kg}^{-1} \mathrm{~h}^{-1}$ starting 21:30 $\mathrm{h}$ after unilateral renal ischemia or nephrectomy until the end of the experiment.

\section{Induction of unilateral renal ischemia and unilateral nephrectomy}

Rats were anaesthetized using diethyl ether (99.7\%; Merck, Darmstadt, Germany) and placed supine on a heated surgical table to keep the animal warm at $37 \pm 1{ }^{\circ} \mathrm{C}$, which was monitored through a rectal probe connected to a thermistor 
(Physitemp BAT-12; Texas Scientific Instruments, San Antonio, Texas, USA). A 1-ml blood sample was taken from the tail, centrifuged, and its plasma was aliquoted. One part of it used for an immediate measurement of $\mathrm{Na}^{+}, \mathrm{K}^{+}$and osmolality, a second part was kept in the refrigerator for later assessment of creatinine and urea, and a third part was frozen in liquid nitrogen and preserved at $-70{ }^{\circ} \mathrm{C}$ for later determination of malondialdehyde (MDA) and metabolites of nitric oxide (NO). In each rat, heparin (100 units) was i.p. injected at 15 min before surgery to prevent intravascular blood clotting. A midline electrosurgical laparotomy (Surgistat; Valleylab, Colorado, USA) was performed and the right renal pedicle was exposed and examined using a surgical microscope (SZ6745TR, Optika; Via Rigla, Italia). For induction of UNX, the right renal pedicle was ligated using 4-0 silk suture at two points, and then the right kidney was removed. In rats subjected to UIR, the right renal pedicle was occluded for $2 \mathrm{~h}$ using a non-traumatic clamp, and blood reflow was confirmed by the return of normal colour to the kidney. In the sham-operated group, blood sampling and all surgical procedures were performed, but the right renal pedicle was only manipulated. The abdominal incision was sutured at two layers by 3-0 silk, and the rat was returned to an individual cage.

\section{Preparation of rats for measuring renal and pulmonary parameters}

At $20 \mathrm{~h}$ after unilateral nephrectomy, unilateral renal ischemia or shamoperation, each rat was re-anaesthetized using an i.p. injection of pentobarbital sodium (Sigma) at $60 \mathrm{mg} \mathrm{kg}^{-1}$ and placed supine on a heated surgical table. A tracheotomy was performed and supplemental oxygen was blown across the end of the tube. A cannula was inserted into the right femoral vein to infuse normal saline at $3 \mathrm{ml} \mathrm{h}^{-1}$ using a Syringe-infusion pump (SEP-10S; UAB Viltechmeda, Lithuania), and administration of 
bolus doses of pentobarbital sodium when needed. Another cannula was placed into the right femoral artery and connected to a pressure transducer (MLT844; ADInstruments, Bella Vista, NSW, Australia) for continuous recording of arterial pressure by means of a PowerLab/4SP data acquisition system (ADInstruments). Then, the midline abdominal suture was opened and each ureter was separately cannulated. The left renal artery was carefully cleared under the surgical microscope, and the probe (MA1PRB) of a transonic perivascular flowmeter (T402-PB; Transonic System Inc., Ithaca, Newyork, USA) was put around it to measure renal blood flow by PowerLab. In addition, a pulse transducer (BNC, MLT1010; ADInstruments) was fixed on top of the thorax for continuous recording of respiratory rate by PowerLab. The animal was allowed to have $30 \mathrm{~min}$ of equilibration, while aminoguanidine administration in the $3 \mathrm{ml} \mathrm{h}^{-1}$ saline infusion was started from the beginning of this period in the two treated-groups. After equilibration period, a $0.2 \mathrm{ml}$ blood sample was taken for immediate analysis of acidbase status and gases, and then a 2-h clearance period was undertaken over the 22-24 $\mathrm{h}$ period with collecting urine from each kidney in a separate pre-weighed container. An arterial blood sample $(1 \mathrm{ml})$ was taken into a cooled heparinized syringe at the end of the clearance period, of which $0.2 \mathrm{ml}$ was analyzed for acid-base status and gases. The remainder of blood was centrifuged and part of the plasma was used for immediate measurement of $\mathrm{Na}^{+}, \mathrm{K}^{+}$and osmolality, and the remainder of it was aliquoted and preserved as described before for later assaying of creatinine, urea, MDA and NOmetabolites. The red blood cells were resuspended in an equivalent volume of saline and re-infused into the animal. Thereafter, the tracheal tube was aspirated and connected to a ventilator (SAR-830/AP; CWE Inc., Ardmore, USA) for respiring room air at a rate of 60 breaths $\min ^{-1}$ with a tidal volume of $1 \mathrm{ml}$ per $100 \mathrm{~g}$ of body weight. After $10 \mathrm{~min}$ of 
ventilation, an arterial blood sample was taken to measure arterial oxygen tension $\left(\mathrm{P}_{\mathrm{a}} \mathrm{O}_{2}\right)$ and by dividing it to inspired fraction of oxygen $\left(\mathrm{F}_{\mathrm{i}} \mathrm{O}_{2}\right)$ in room air $(21 \%)$, the ratio of $\mathrm{P}_{\mathrm{a}} \mathrm{O}_{2}$ to $\mathrm{F}_{\mathrm{i}} \mathrm{O}_{2}\left(\mathrm{P}_{\mathrm{a}} \mathrm{O}_{2} / \mathrm{F}_{\mathrm{i}} \mathrm{O}_{2}\right)$ was calculated. In addition, the pressure of airways was measured during expiration by a pressure transducer (MLT0699-no stopcock; ADInstruments) connected to the PowerLab, and airway resistance was calculated by dividing airway pressure to the specified and constant air flow (Bolle et al. 2008).

Since it was not possible to evaluate all other pulmonary functional parameters in one rat, each group was subdivided into 3 subgroups. In the subgroup A, the static lung compliance was determined from the inflation pressure-volume curve. After infusing 100 units of heparin, the thorax was opened through a median sternotomy, and the ribs were spread apart using clamps to completely expose the lungs. The rat was disconnected from the ventilator and sequential $2 \mathrm{ml}$ injections of air were delivered, with repeated measure of airway pressure at $5 \mathrm{sec}$ after each injection until a final airway pressure of $30 \mathrm{cmH}_{2} \mathrm{O}$ was reached. The rat was the re-connected to the ventilator for $30 \mathrm{sec}$, and the procedure repeated three times (Joss-Moore et al. 2011).

In the subgroup B, bronchoalveolar lavage fluid (BALF) was obtained by slowly instilling $3 \mathrm{ml}$ of warmed $\left(\sim 37^{\circ} \mathrm{C}\right)$ PBS with $\mathrm{pH}=7.4$ into lung through the tracheal tube. After $30 \mathrm{sec}$, the fluid was withdrawn by gentle suction, and the process was repeated twice. $50 \mu \mathrm{l}$ of BALF was stained with $50 \mu$ of Turk's solution, and the total number of cells was counted by means of a haematocytometer. The remainder of BALF was centrifuged at $1500 \mathrm{rpm}$ for $10 \mathrm{~min}$ at $4{ }^{\circ} \mathrm{C}$, and the supernatant was removed. The BALF supernatant together with a plasma sample, which had been obtained from rat before taking BALF, were stored at $-20{ }^{\circ} \mathrm{C}$ (Kim et al. 2006; Rodrigo et al. 2006). Protein concentrations of the samples were measured by the Bradford method and 
presented as the ratio of BALF to plasma protein concentrations $\times 1000\left([\mathrm{Pr}]_{\mathrm{BALF}} /[\mathrm{Pr}]_{\mathrm{P}}\right.$ $\times 1000)$.

In the subgroup $\mathrm{C}$ of each group, changes in vascular permeability were assessed by quantitating extravasation of Evans blue dye (EBD) into the kidney and lung tissues. Infusion of 2\% EBD (Sigma) at a dose of $20 \mathrm{mg} \mathrm{kg}^{-1}$ was done for $5 \mathrm{~min}$ before the hour of 23. One hour later, heparin (100 units) was infused and then the thorax was opened to allow insertion of two needles into left ventricle up to the aorta and right ventricle up to the pulmonary artery. Two separate syringes containing warmed PBS $\left(\sim 37^{\circ} \mathrm{C}\right)$ with $\mathrm{pH}=7.4$ were fixed at a height of $20 \mathrm{~cm}$ and connected to the needles. Flow of PBS completely washed the renal and pulmonary vascular system and exited through inferior vena cava and pulmonary veins, respectively. Finally, the lungs and kidneys were removed, frozen in liquid nitrogen, and preserved at $-70{ }^{\circ} \mathrm{C}$ (Awad et al. 2006). After weighing the lungs and kidneys, they were separately homogenized in formamide (Sigma) at 4 and $6 \mathrm{ml}$ per gram wet tissue, respectively. The homogenized tissues were incubated at $60^{\circ} \mathrm{C}$ for 18 hours, and then centrifuged at $12000 \mathrm{rpm}$ for $1 \mathrm{~h}$. The absorbance of supernatant was measured at $620 \mathrm{~nm}$ using a microplate reader (Synergy HT, BioTeck Instruments; Winooski, USA), and EBD concentration was calculated against a standard curve and presented as $\mu$ g EBD per gram of wet tissue (Kim et al. 2006).

\section{Measurement of blood and urine variables and renal functional parameters}

Measurements of arterial oxygen tension $\left(\mathrm{P}_{\mathrm{a}} \mathrm{O}_{2}\right)$, carbon dioxide tension $\left(\mathrm{P}_{\mathrm{a}} \mathrm{CO}_{2}\right)$, acidity $\left(\mathrm{pH}_{\mathrm{a}}\right)$, and bicarbonate concentration $\left(\left[\mathrm{HCO}_{3}{ }^{-}\right]_{\mathrm{a}}\right)$ were performed using an Easy blood-gas analyzer (Medica Corporation, Bedford, Massachusetts, USA). Plasma and urine samples were assayed for creatinine and urea nitrogen in $\mathrm{mg} \mathrm{dl}^{-1}$ by means of an 
autoanalyzer (RA 1000; Technicon Instruments, USA), $\mathrm{Na}^{+}$and $\mathrm{K}^{+}$in $\mu \mathrm{mol} \mathrm{ml}{ }^{-1}$ with an EasyLyte analyzer (Medica Corporation), and osmolality in mosm $\mathrm{kgH}_{2} \mathrm{O}^{-1}$ using a cryoscopic osmometer (Osmomat-010; Gonotec GmbH, Berlin, Germany). The volume of collected urine from each kidney during the clearance period was measured gravimetrically, and its urine flow rate per gram of kidney weight $\left(\mu 1 \min ^{-1} \mathrm{gkw}^{-1}\right)$ was calculated. Creatinine clearance as an estimate of glomerular filtration rate (GFR), absolute and fractional excretion of $\mathrm{Na}^{+}, \mathrm{K}^{+}$and urea, as well as osmolar clearance and free-water reabsorption were calculated by using standard formulae (Moosavi et al. 2011; Moosavi et al. 2013).

\section{Malondialdehyde (MDA) assay}

Plasma level of MDA was determined using a TBARS assay (Barros et al. 1999). The serial concentrations of 1,1,3,3-tetraethoxy propane (Sigma) were prepared from 0.25 to $5 \mu \mathrm{mol} \mathrm{l}^{-1}$, and used as standards. A mixture of $0.25 \mathrm{~N} \mathrm{HCl}, 20 \%$ tricholoro acetic acid (TCA) and $0.8 \%$ tribarbituric acid was incubated at $60{ }^{\circ} \mathrm{C}$ for 20 min in a water bath. Then, $800 \mu \mathrm{l}$ of the reagent mixture was added to $200 \mu \mathrm{l}$ of each plasma and standard sample, and incubated at $90{ }^{\circ} \mathrm{C}$ for $60 \mathrm{~min}$. After cooling, they were centrifuged at $4000 \mathrm{rpm}$ for $10 \mathrm{~min}$, and the absorbance of coloured supernatant was read at $532 \mathrm{~nm}$ using a microplate reader. The MDA levels were calculated as $\mu \mathrm{mol}$ per lit of plasma using the standard curve.

\section{Measurement of NO metabolite}

Nitrite and nitrate are the main oxidation products of $\mathrm{NO}$ in a reaction with oxygen. Therefore, the nitrite/nitrate concentrations were measured by Griess method in plasma samples to indicate their NO level (Miranda et al. 2001). Initially, plasma samples were deproteinized using 99\% ethanol and centrifuged. Quantitation of nitrite 
was based on its reaction with a mixture of $0.1 \% \mathrm{~N}$-(1-Naphtyl) ethylene diamin dihydrochloride (NEDD) in 5\% $\mathrm{HCl}(25 \mu \mathrm{l})$ and $2 \%$ sulphanilamide $(25 \mu \mathrm{l})$, which were added to $50 \mu \mathrm{l}$ of deproteinized plasma samples in duplicate and kept in a water bath at $37{ }^{\circ} \mathrm{C}$ for $15 \mathrm{~min}$. The optical densities were measured at $540 \mathrm{~nm}$ using a microplate reader. Thereafter, nitrate was quantitated by reducing it to nitrite via addition of vanadium (III) chloride $(50 \mu \mathrm{l})$ to each sample, incubating for $15 \mathrm{~min}$ at 37 ${ }^{\circ} \mathrm{C}$, and reading again absorbances at $540 \mathrm{~nm}$. Total nitrite/nitrate $\left(\mathrm{NO}_{2}{ }^{-} / \mathrm{NO}_{3}{ }^{-}\right)$ concentrations were calculated as $\mu \mathrm{mol}$ per lit of plasma using the standard curve generated from the serial concentrations of $\mathrm{NaNO}_{2}\left(0-100 \mu \mathrm{mol} \mathrm{l}^{-1}\right)$.

\section{Statistical Analysis}

Data are presented as means \pm SEM. The within group comparisons were assessed using the Student's paired $t$ test, and the between group comparisons were performed by means of one-way analysis of variance (ANOVA) followed by Duncan's post-hoc test, and then the least significant difference (LSD) test for determining the exact level of $P$-values. SPSS version 11.5 software (SPSS, Chicago, Illinois) was used for all data analyses, and significance was taken at $P<0.05$. 


\section{RESULTS}

\section{Plasma NO-metabolites and MDA}

Fig. 1A shows that basal plasma levels of $\mathrm{NO}_{2}{ }^{-} / \mathrm{NO}_{3}{ }^{-}$prior to $\mathrm{UNX}$, UIR or sham-operation (pre-values) in all treated and untreated groups were all the same. The plasma level of $\mathrm{NO}_{2}{ }^{-} / \mathrm{NO}_{3}{ }^{-} 24 \mathrm{~h}$ after the ischemic challenge (post-value) was elevated in the UIR group with respect to its pre-value $\left(87.0 \pm 12.6\right.$ vs $\left.62.6 \pm 9.0 \mu \mathrm{mol} 1^{-1}, P<0.5\right)$ and also post-values of the sham, treated-UIR and UNX groups (all $P<0.05$ ). The postvalues of plasma $\mathrm{NO}_{2}{ }^{-} / \mathrm{NO}_{3}{ }^{-}$were not different in the sham, treated-UIR, UNX and treated-UNX groups.

The pre-values of plasma MDA (Fig. 1B) were the same in all groups. However, 2-h unilateral ischemia and 24-h reperfusion markedly elevated plasma MDA in the UIR group compared to its basal value $\left(1.20 \pm 0.10\right.$ vs $\left.0.54 \pm 0.05 \mu \mathrm{mol} 1^{-1}, P<0.01\right)$ and the post-values in the sham and UNX groups (both $P<0.001$ ). In the treated-UIR group, post-value of plasma MDA remained equal to its basal value and also to those of the sham and UNX groups, and was lower than that of the UIR group $(P<0.001)$. The postvalue of plasma MDA in the treated-UNX group decreased from its pre-value $(P<0.05)$ but it was not statistically lower than post-values of plasma MDA in the UNX and sham groups.

\section{Plasma variables}

The basal values for plasma osmolality and plasma concentrations of $\mathrm{Na}^{+}, \mathrm{K}^{+}$, creatinine, and urea nitrogen were the same for all five groups (Table 1). The postvalues of plasma $\mathrm{Na}^{+}$and osmolality increased from their pre-values in all groups $(P<$ 0.05-0.001). The post-value of plasma creatinine in the UIR group was higher than its 
pre-value $(P<0.05)$ and also the post-values of the sham, treated-UIR and UNX groups (all $P<0.05$ ).

\section{Arterial blood variables, heart rate, and body weight}

Table 2 shows that the weight loss following UIR, UNX or sham-operation, and the levels of $\mathrm{p}_{\mathrm{a}} \mathrm{O}_{2}, \mathrm{p}_{\mathrm{a}} \mathrm{CO}_{2}, \mathrm{pH}_{\mathrm{a}}$ and $\left[\mathrm{HCO}_{3}{ }^{-}\right]_{\mathrm{a}}$, as well as mean arterial pressure and heart rate during the 2-h clearance period were not different among the treated and untreated groups.

\section{Renal weight, capillary permeability and hemodynamics}

The percent of kidney weight per body weight (KW/BW; Fig. 2A) in the left non-ischemic kidney (NIK) of the UIR group was equal to that of the left kidney of sham group $(0.383 \pm 0.015 \%)$, but it was increased in the right post-ischemic kidney (PIK, $0.461 \pm 0.025 \%)$ with respect to its contralateral NIK $(0.403 \pm 0.015 \%, P<0.05)$ and the right kidney of sham group $(0.391 \pm 0.019 \%, P<0.05)$. The KW/BW in PIK of the treated-UIR group $(0.417 \pm 0.005 \%)$ was higher than its NIK $(P<0.01)$, but it was not statistically different from those of the equivalent kidney in the UIR and sham groups. In the UNX group, KW/BW of the remnant kidney $24 \mathrm{~h}$ after the right nephrectomy $(0.450 \pm 0.014 \%)$ was higher than those of the left kidney of the sham and UIR groups $(P<0.001$ and $P<0.01$, respectively). However, the KW/BW was reduced in the treated-UNX group compared to UNX group $(P<0.05)$, and reached levels equivalent to that in the sham and treated-UIR groups.

Fig. 2B shows that the concentration of EBD in kidney tissue 24 after the ischemic challenge was significantly increased some 4-folds in the PIK from those of the equivalent kidney of sham group $\left(31.9 \pm 5.0 \mu \mathrm{g} \mathrm{gkw}^{-1}\right)$ and the contralateral NIK (both $P<0.001$ ). In the treated-UIR group, EBD of PIK was reduced from that of the 
UIR group $(P<0.001)$, but it was still higher than those of the right kidney of sham group $(P<0.001)$ and the NIK $(P<0.01)$. The values of EBD in NIK of the UIR and treated-UIR groups and remnant kidney of the UNX and treated-UNX groups and the left kidney of sham group were similar.

Renal blood flow was measured only in the left kidney of all groups (Fig. 2C). Blood flow of NIK during 22-24 h of reperfusion period showed no difference between the UIR and treated-UIR groups $\left(10.3 \pm 0.9\right.$ and $11.8 \pm 0.8 \mathrm{ml} \mathrm{min}^{-1} \mathrm{gkw}^{-1}$, respectively), but it was statistically higher only in the treated-UIR group $(P<0.05)$ than the left kidney of sham group $\left(9.2 \pm 0.2 \mathrm{ml} \mathrm{min}^{-1} \mathrm{gkw}^{-1}\right)$. There were large equal increases in blood flow of remnant kidney in the UNX and treated-UNX groups (14.1 \pm 0.8 and $13.8 \pm 1.1 \mathrm{ml} \mathrm{min}^{-1} \mathrm{gkw}^{-1}$, respectively) with respect to that of the left kidney of sham group $(P<0.001$ and $P<0.01$, respectively). In addition, blood flow in remnant kidney compared to NIK was higher significantly $(P<0.01)$ in the UNX group than the UIR group and non-significantly $(P=0.09)$ in the treated-UNX group than the treated-UIR group.

The severe ischemic challenge resulted in only 3 from 10 rats in the UIR group having urine output in their PIK during the 2 h clearance period, while PIK of 9 from 10 rats in the treated-UIR group had urine output with the sufficient volumes in 7 rats for measuring renal excretory parameters. It is evident from Fig. 2D that creatinine clearance during the 2-h clearance period in PIK of the 3 rats in the UIR group was reduced by $99.9 \%$ from that of the equivalent kidney in sham group $(0.84 \pm 0.50 \mathrm{vs}$ $\left.642.87 \pm 121.62 \mu \mathrm{min}^{-1} \mathrm{gkw}^{-1}, P<0.001\right)$, While, the decrease in creatinine clearance of the PIK was slightly attenuated in the treated-UIR group $\left(36.29 \pm 3.04 \mu \mathrm{min}^{-1} \mathrm{gkw}^{-1}\right)$ with respect to the UIR group $(P<0.001)$. On the other hand, there were equal increases 
in creatinine clearance of NIK in the UIR and treated-UIR groups $(994.23 \pm 77.39, P<$ 0.01 and $1168.91 \pm 60.57 \mu \mathrm{min}^{-1} \mathrm{gkw}^{-1}, P<0.001$, respectively) compared to the left kidney of sham group $\left(548.07 \pm 118.29 \mu \mathrm{min}^{-1} \mathrm{gkw}^{-1}, P<0.001\right)$. In addition, there were similar increases in creatinine clearance in the remnant kidney of the UNX and treated-UNX groups $\left(1271.71 \pm 139.61\right.$ and $1285.88 \pm 136.52 \mu \mathrm{l} \mathrm{min}^{-1} \mathrm{gkw}^{-1}$, respectively) compared to the equivalent kidney in sham group (both $P<0.001$ ). The creatinine clearance of the remnant kidney compared to NIK was significantly higher in the UNX group than the UIR group $(P<0.05)$, but not in the treated-UNX group than the treated-UIR group.

\section{Renal excretion of sodium, potassium and urea}

Absolute $\mathrm{Na}^{+}$-excretion (Fig. 3A) was markedly diminished in PIK of both UIR and treated-UIR groups $(P<0.01$ and $P<0.05$, respectively) compared to the equivalent right kidney of the sham group $\left(0.44 \pm 0.08 \mu \mathrm{mol} \mathrm{min}{ }^{-1} \mathrm{gkw}^{-1}\right)$, but it was higher in the treated-UIR group than the UIR group $(P<0.05)$. Absolute $\mathrm{Na}^{+}$-excretion of the nonchallenged kidney was elevated in the UIR and UNX group $(2.81 \pm 0.73, P<0.05$ and

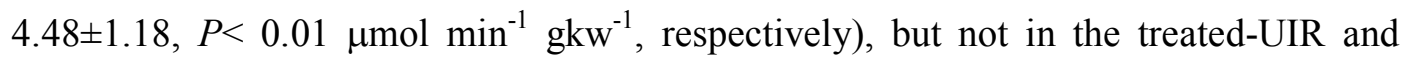
treated-UNX groups, compared to the left kidney of the sham group. Moreover, absolute $\mathrm{Na}^{+}$-excretion in the kidney of UNX group was significantly higher than that of the treated-UNX group $(P<0.01)$, but its level in NIK of the treated-UIR group was not statistically different from the UIR group.

Fractional $\mathrm{Na}^{+}$-excretion (Fig. 3B) in PIK of the UIR group showed very severe rise in comparison to the right kidney of sham group $(99.28 \pm 37.01 \%$ vs $0.50 \pm 0.10 \%$, $P<0.001)$. Fractional $\mathrm{Na}^{+}$-excretion in PIK of the treated-UIR group was markedly reduced $(3.80 \pm 0.44 \%)$ compared to the UIR group $(P<0.01)$, but it was still higher than 
that of the right kidney of sham group $(P<0.01)$. However, fractional $\mathrm{Na}^{+}$-excretion in the non-challenged kidney of the UIR, treated-UIR and treated-UNX groups were not different from each other or that of the equivalent kidney of sham group (1.20 $\pm 0.34 \%)$. Fractional $\mathrm{Na}^{+}$-excretion of remnant kidney in the UNX group $(2.43 \pm 0.64 \%)$ was higher than the treated-UNX group and left kidney of sham group (both $P<0.05$ ).

It is apparent from Fig. $3 \mathrm{C}$ that absolute $\mathrm{K}^{+}$-excretion in the PIK of the UIR and treated-UIR groups were greatly reduced with respect to the equivalent kidney of the sham group $\left(0.68 \pm 0.07 \mu \mathrm{mol} \mathrm{min} \mathrm{gkw}^{-1}\right.$, both $\left.P<0.001\right)$, while it was higher in the treated-UIR group than the UIR group $\left(0.146 \pm 0.019\right.$ vs $0.009 \pm 0.001 \mu \mathrm{mol} \mathrm{min}{ }^{-1} \mathrm{gkw}^{-1}$, $P<0.01)$. However, absolute $\mathrm{K}^{+}$-excretion in the non-challenged kidney of the UIR, treated-UIR, UNX and treated-UNX groups were equal and higher than that of the left

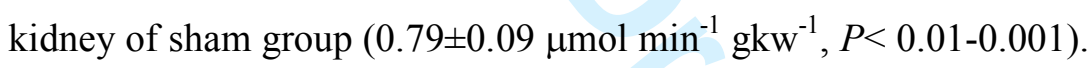

Fractional $\mathrm{K}^{+}$-excretion (Fig. 3D) was greatly elevated in PIK of the UIR group compared to the right kidney of the sham group $(559.30 \pm 280.14 \%$ vs $29.49 \pm 4.83 \%, P<$ 0.01). Although fractional $\mathrm{K}^{+}$-excretion of PIK was markedly decreased in the treatedUIR group $(103.57 \pm 14.02 \%)$ compared to the UIR group $(P<0.05)$, it was still higher than that of the right kidney of sham group $(P<0.01)$. Fractional $\mathrm{K}^{+}$-excretion in nonchallenged kidney of the UIR, treated-UIR, UNX and treated-UNX groups remained equal to each other and that of the left kidney of sham group $(39.35 \pm 3.86 \%)$.

Absolute urea-excretion (Fig. 3E) was markedly decreased in the PIK of the UIR and treated-UIR groups compared to the equivalent kidney of the sham group $\left(2.36 \pm 0.36 \mu \mathrm{mol} \mathrm{min}{ }^{-1} \mathrm{gkw}^{-1}\right.$, both $\left.P<0.001\right)$, but it was higher in the treated-UIR group than the UIR group $\left(0.151 \pm 0.015\right.$ vs $\left.0.005 \pm 0.004 \mu \mathrm{mol} \mathrm{min} \mathrm{gkw}^{-1}, P<0.001\right)$. While, absolute urea-excretion of the non-challenged kidneys in the UIR, treated-UIR, 
UNX and treated-UNX groups were higher than that of the left kidney of the sham

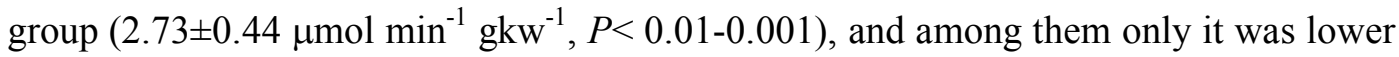
in the treated-UNX group than the UNX group $(P<0.05)$.

Fig. 3F shows that there was no significant difference in fractional ureaexcretion of the left or right kidney of the sham group $(58.54 \pm 8.04 \%$ and $44.92 \pm 11.2 \%$, respectively) with their equivalent kidneys in the other 4 groups.

\section{Osmolar clearance, urine flow rate and urine concentrating ability}

It can be seen in Fig. 4A that osmolar clearance was greatly reduced in the PIK of the UIR and treated-UIR groups with respect to the equivalent kidney of sham group $\left(16.32 \pm 2.08 \mu \mathrm{min}^{-1} \mathrm{gkw}^{-1}\right.$, both $\left.P<0.001\right)$, while it was higher in the PIK of the treated-UIR group than the UIR group $\left(2.30 \pm 0.14\right.$ vs $0.59 \pm 0.19 \mu \mathrm{min}^{-1} \mathrm{gkw}^{-1}, P<$ 0.001). Osmolar clearance in NIK of the UIR group and remnant kidney of the UNX group, but not in both treated-groups, were significantly higher $(P<0.01$ and $P<0.001$, respectively) than the left kidney of sham group $\left(20.97 \pm 3.45 \mu 1 \mathrm{~min}^{-1} \mathrm{gkw}^{-1}\right)$. In addition, osmolar clearance was significantly lower in the kidney of the treated-UNX group than the UNX group $(P<0.01)$.

Free-water reabsorption (Fig. 4B) was largely reduced in PIK of the UIR and treated-UIR groups with respect to the equivalent kidney of the sham group $(12.35 \pm 1.93$ $\mu 1 \min ^{-1} \mathrm{gkw}^{-1}$, both $P<0.001$ ), while the treated-UIR group had a higher free-water reabsorption in PIK than the UIR group $\left(1.53 \pm 0.11\right.$ vs $0.12 \pm 0.05 \mu \mathrm{lmin}^{-1} \mathrm{gkw}^{-1}, P<$ 0.001). Free-water reabsorption was increased in non-challenged kidney of all 4 groups compared to that of the left kidney of sham group $\left(14.34 \pm 2.60 \mu \mathrm{min}^{-1} \mathrm{gkw}^{-1}, P<0.05\right.$ 0.001). Free-water reabsorption was not different in the NIK of the UIR and treated- 
UIR groups, but it was higher in the UNX group than the treated-UNX group $(P<$ $0.001)$.

Urine flow rate (Fig. 4C) of PIK in the UIR and treated-UIR groups $(0.47 \pm 0.23$ and $0.77 \pm 0.07 \mu \mathrm{min}^{-1} \mathrm{gkw}^{-1}$, respectively) were equal, and both of them were lower than that of the right kidney of sham group $\left(3.97 \pm 0.36 \mu \mathrm{min}^{-1} \mathrm{gkw}^{-1}\right.$, both $\left.P<0.001\right)$. Urine flow rate in NIK of the UIR group and remnant kidney of the UNX group, but not in those of the treated-groups, were significantly elevated $(P<0.05$ and $P<0.01$, respectively) compared to the left kidney of the sham group $\left(6.63 \pm 0.95 \mu \mathrm{min}^{-1} \mathrm{gkw}^{-1}\right)$. Urine flow rate was statistically lower in the kidney of the treated-UNX group than the UNX group $(P<0.01)$, but not in NIK of the treated-UIR group than the UIR group.

Fig. 4D shows that urine osmolality in PIK of the treated-UIR group and the

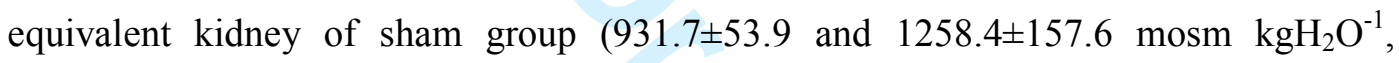
respectively) were not statistically different, but both were higher than the PIK of UIR group (437.3 \pm 62.7 mosm $\mathrm{kgH}_{2} \mathrm{O}^{-1}$, both $\left.P<0.01\right)$. Urine osmolality in NIK of the UIR group and remnant kidney of the UNX group remained unchanged but it was elevated in the NIK of the treated-UIR group and remnant kidney of the treated-UNX group (both $P<0.01)$ with respect to the left kidney of the sham group $\left(979.3 \pm 84.4\right.$ mosm $\left.\mathrm{kgH}_{2} \mathrm{O}^{-1}\right)$. In addition, there was a significant higher urine osmolality in the NIK of the UIR compared to the treated-UIR groups $(P<0.05)$, but not between remnant kidney of the UNX and treated-UNX groups.

\section{Pulmonary functional and capillary permeability variables}

Table 3 presents the levels of respiratory rate during the 2 -h clearance period, as well as airway resistance, total number of cell in bronchoalveolar lavage fluid (BALF), ratio of BALF to plasma protein concentrations $\left([\operatorname{Pr}]_{\mathrm{BALF}} /[\operatorname{Pr}]_{\mathrm{P}} \times 1000\right)$, and 
concentration of EBD in lung tissue $24 \mathrm{~h}$ after unilateral renal ischemia, UNX or shamoperation in the treated and untreated groups were the same. The ratio of arterial oxygen partial pressure to inspired fraction of oxygen $\left(\mathrm{P}_{\mathrm{a}} \mathrm{O}_{2} / \mathrm{FiO}_{2}\right)$ was only slightly reduced in the UIR group with respect to the sham, treated-UIR and UNX groups $(P<0.01, P<$ 0.05 and $P<0.05$, respectively).

\section{Static lung compliance}

The static lung compliance was determined from inflation volume-pressure curves in opened chest rats and presented for the sham, UIR and treated-UIR groups in Fig. 5A and the sham, UNX and treated-UNX groups in Fig. 5B. The volume-pressure curves for all groups were similar and showed that the slopes of pressure to volume changes were increased at low and high volumes (low compliance) and decreased at middle volumes (high compliance). 


\section{DISCUSSION}

This study demonstrated that unilateral AKI induced by 2-h ischemia and 24-h reperfusion led to development of systemic oxidative stress and increment of plasma NO level by iNOS activation that mediated part of its distant effects on contralateral NIK, but did not cause any vascular and alveolar functional disturbances in the lung. Hence, the pathogenesis of multi-organ dysfunction can vary between organs.

The 2-h unilateral renal ischemia followed by $24 \mathrm{~h}$ reperfusion led to rises in plasma levels of NO and ROS which were prevented by the co-treatment with $\alpha$ tocopherol and aminoguanidine, indicating that this challenge induced iNOS activation to elevate plasma NO. However, the no change of plasma NO in UNX, treated-UNX and sham groups implied that the basal systemic NO is not produced by iNOS and not affected by UNX. In the PIK of UIR group, the capillary permeability was very highly increased and caused more transfusion of fluid into the renal interstitium and edema formation, as evidenced by a rise in its $\mathrm{KW} / \mathrm{BW}$. The increased vascular permeability and $\mathrm{KW} / \mathrm{BW}$ were partially improved in PIK of the treated-UIR group indicating that the renal ischemia-induced iNOS activity and ROS production were responsible in part for these responses. It has been shown in other studies that the injured epithelial cells and leukocyte infiltration aggravated endothelial injury in AKI through enhanced production of chemokines/cytokines, ROS and arachadonic metabolites, and expression of iNOS (Araujo and Welch 2006; Chatterjee et al. 2002; Legrand et al. 2009; Sharfuddin et al. 2012).

Anaesthesia and surgery caused rises in plasma $\mathrm{Na}^{+}$and osmolality as well as concomitant loss of about $5 \%$ in body weight after $24 \mathrm{~h}$ in all groups, which were probably due to an imbalance between intake and output of water. Creatinine clearance 
in the PIK was very severely reduced by $99.9 \%$ during the 2 -h clearance period. It has been shown that endothelial cell injury in AKI is associated with an imbalance between production of vasodilators and vasoconstrictors that increases renal arteriolar resistance and also with vascular congestion, which resulted in a fall of renal blood flow (Sharfuddin et al. 2012; Sutton 2009). The reduced renal blood flow in conjunction with obstructing intratubular casts would elevate Bowman's space pressure, leading to a decrease in GFR (Devarajan 2006; Sharfuddin et al. 2012). The severities of tubular epithelial injury and intratubular casts were so high in the PIK of UIR group that its urine flow was completely blocked in 7 of 10 rats. The fact that GFR was marginally higher in the PIK of the treated-UIR group was compatible with the view that increased ROS and NO mediated via iNOS in response to the renal ischemia contributed to the decreased renal hemodynamics (Chatterjee et al. 2003; Sharfuddin et al. 2012). The improved capillary permeability in PIK of the treated-UIR group implied that endothelial injury vascular congestion and increased intrarenal vasoconstriction were attenuated. However, the intensity of tubular damage induced by the 2 -h renal ischemia was so severe that $\alpha$-tochopherol and aminoguanidine could not appreciably improve them and, hence, GFR was only slightly ameliorated in PIK of the treated-UIR group.

The excretory data for PIK of the UIR group were somehow unreliable, because of obtaining from only 3 rats with urine flow. The large reductions in absolute $\mathrm{Na}^{+}-\mathrm{K}^{+}-$ and urea-excretion and osmolar clearance in the PIK of the UIR group were most likely due to the severe fall in GFR, which were reflected in the hugely increased fractional $\mathrm{Na}^{+}$- and $\mathrm{K}^{+}$-excretion indicating reabsorption of solutes were defected due to the intensive tubular injury. It has been shown that renal IR leads to epithelial injury mainly in tubular segments with high active transport (Moosavi et al. 2009; Sharfuddin et al. 
2012). Moreover, impaired countercurrent multiplication at the Henle's loop in PIK of the UIR group was most likely responsible for the low urine osmolality and diminished free-water reabsorption. Despite the fall of free-water reabsorption, the greatly decreased osmolar clearance resulted in a reduction of urine flow rate, as urine flow rate $=$ osmolar clearance - free-water reabsorption. There are a number of reports indicating that iNOS inhibitors and antioxidants improve IR-induced renal tissue damage and function (Chatterjee et al. 2002; Onem et al. 2009; Wongmekiat et al. 2007). This view would be supported by the present findings that epithelial injury and tubular malabsorption were attenuated in the PIK of the treated-UIR group, as fractional $\mathrm{Na}^{+}-$ and $\mathrm{K}^{+}$-excretion were reduced in spite of a higher GFR compared to the UIR group. As noted above, the 2-h unilateral renal ischemia-induced tissue injury and tubular dysfunction were so severe in the PIK that $\alpha$-tochopherol and aminoguanidine could only slightly ameliorate them. The result was little elevations in absolute $\mathrm{Na}^{+}-, \mathrm{K}^{+}-$, and urea-excretion and osmolar clearance due to improved GFR in the treated-UIR group with respect to the UIR group. Moreover, the slightly improved tubular cell injury and osmolar clearance caused rises in free-water reabsorption and urine osmolality. However, the elevated free-water reabsorption prevented the increase in urine flow rate due to the raised osmolar clearance in PIK of the treated-UIR group compared to the UIR group.

The contralateral NIK of the UIR group exhibited non-significant elevation in renal blood flow and incomplete compensatory increase in GFR during the 22-24 h of reperfusion, which resulted in a rise of plasma creatinine. During the equivalent period in the UNX group, the remnant kidney had full compensatory increases in renal blood flow and GFR that kept plasma creatinine and urea at their basal levels, consistent with 
other reports (Aytac et al. 2008; Nagasu et al. 2012). It is evident from these results that the PIK has a distant effect on the NIK to prevent its full compensatory hemodynamic overfunction in the UIR model. In addition, the increases in renal blood flow and GFR in the NIK of the treated-UIR group indicated that NO-derived from iNOS and ROS act as the systemic mediators for the hemodynamic responses of NIK to injury of PIK in the UIR model. The elevation of renal blood flow by $153 \%$ in the remnant kidney of the treated-UNX group and $128 \%$ in the NIK of the treated-UIR group implied a relatively greater vasoconstriction in the NIK, suggesting that other factors play roles in mediating vascular responses between the NIK and PIK. Moreover, it was possible that a higher efferent arteriolar constriction in NIK of the treated-UIR group helped cause sufficient compensatory increase in its GFR. On the other hand, the observation that there was no difference in renal blood flow and GFR between the UNX and treated-UNX groups indicated that ROS and NO-derived from iNOS have no role in hemodynamic overfunction of the remnant kidney during acute period following UNX. In other studies (Sigmon et al. 2004; Valdivielso et al. 1999), it was shown that NO was the main mediator for immediate and sustained increases in hemodynamic function of the remnant kidney following UNX. However, Nagasu et al. (2012) demonstrated the importance of NO-derived from eNOS in UNX-induced remnant kidney compensatory hemodynamic function.

The compensatory excretion of solutes and water by NIK in the UIR group and remnant kidney in the UNX group were complete which resulted in maintaining plasma $\mathrm{Na}^{+}, \mathrm{K}^{+}$, urea and osmolality at the same level as the sham group during the 2-h clearance period. The increases in excretion of $\mathrm{Na}^{+}, \mathrm{K}^{+}$and urea elevated osmolar clearance that caused rises in free-water reabsorption and urine flow rate in both 
kidneys. The falls of absolute $\mathrm{Na}^{+}$-excretion, osmolar clearance and urine flow rate in NIK of the treated-UIR group and remnant kidney of the treated-UNX group indicated that co-treatment with $\alpha$-tochopherol and aminoguanidine resulted in stimulation of tubular sodium and water reabsorption. Therefore, PIK also has distant effect on the tubules of the NIK via mediatory actions of ROS and NO-derived from iNOS to cause inhibition of sodium and water reabsorption, which of course is in a positive direction for performance of full compensatory excretory function. On the other hand, there is a possibility that the neural system can be also involved in this interaction between two kidneys via a renorenal reflex. However, it should be noted that the majority of renal sensory neurons are located in the renal pelvis (Ferguson and Bell 1988) and respond to elevating ipsilateral pelvic pressure by increasing their firing rate that reflexly decrease efferent nerve activity to the contralateral kidney, inducing a diuresis and natriuresis. Moreover, the renorenal reflex has been shown to be severely disturbed in PIK of the rats subjected to UIR (Ma et al. 2002).

In the UIR and UNX groups, there was no change in EBD of lung, $[\mathrm{Pr}]_{\mathrm{BALF}} /[\mathrm{Pr}]_{\mathrm{P}}$ and cell numbers of BALF compared to the sham group, which implied that the permeability of the pulmonary capillaries was not disrupted. The inflation volumepressure curves in the opened chest condition were similar in all groups. The levels of airway resistance and respiratory rate in the UIR and UNX groups were also similar to those of the sham group, which indicated normal ventilatory lung function. BIR-induced AKI has been shown to induce ALI via an inflammatory reaction, oxidative stress, reactive nitrogen species and soluble uremic factors. These systemic signals cause activation of resident lung macrophages and recruitment of circulatory neutrophils and macrophages that through release of injurious factors result in ALI (Faubel 2008; Ko et 
al. 2009). In the UIR group of the present study, the extent of unilateral renal ischemia was sufficient to increase systemic reactive oxygen and nitrogen species, but full compensation by the contralateral NIK caused clearance of not only urea, electrolytes and acid-base but also probably most of the pro-inflammatory signalling molecules not to be changed and they remained at their basal plasma levels. The end result was most likely that leukocytes were not activated or recruited to induce vascular endothelial and alveolar epithelial injuries. Although $\mathrm{P}_{\mathrm{a}} \mathrm{O}_{2} / \mathrm{F}_{\mathrm{i}} \mathrm{O}_{2}$ of the UIR group was slightly reduced, it was far from its level of $<300$ in ALI (Ko et al. 2009). As there was a normal pulmonary capillary and ventilatory function in the UIR group, the reason for this small drop in $\mathrm{P}_{\mathrm{a}} \mathrm{O}_{2} / \mathrm{F}_{\mathrm{i}} \mathrm{O}_{2}$ was not clear. However, it may be somehow related to the high levels of systemic ROS and NO-derived from iNOS, because there was no fall of $\mathrm{P}_{\mathrm{a}} \mathrm{O}_{2} / \mathrm{F}_{\mathrm{i}} \mathrm{O}_{2}$ in the treated-UIR group. The other pulmonary capillary and ventilatory parameters were similar between the UIR and treated-UIR groups, indicating that high levels of systemic ROS and NO-derived from iNOS alone do not affect lung function.

In conclusion, the unilateral AKI induced by 2-h unilateral renal ischemia and 24-h reperfusion could not induce ALI, but had distant effects on contralateral NIK through releasing systemic factors, with ROS and NO-derived from activated iNOS being among them. These mediators appear to constrict renal resistance vessels to dampen the compensatory increases in blood flow and glomerular filtration, but decrease tubular reabsorption to help compensatory increases in solutes and water excretion by NIK. 


\section{Acknowledgements}

The authors wish to acknowledge the Vice-Chancellery for Research affairs of Shiraz University of Medical Sciences, Shiraz, Iran, for the financial support of this study (grant number: 91-6134), as the thesis of H. Fatemikia for acquiring M.Sc. degree in physiology. We also thank the personnel of biochemistry laboratory of Namazi hospital for assistance in measuring creatinine and urea nitrogen of plasma and urine samples

The authors state no conflict of interest. 


\section{References}

Araujo, M., Welch, W.J. 2006. Oxidative stress and nitric oxide in kidney function. Curr. Opin. Nephrol. Hypertens. 15(1): 72-77. PMID:16340670

Awad, A.S., Okusa, M.D. 2007. Distant organ injury following acute kidney injury. Am. J. Physiol. 293(1): F28-F29. PMID:17429033

Awad, A., Ye, H., Huang, L., Li, L., Foss. F.W. Jr., Macdonald, T.L., et al. 2006. Selective sphingosine 1-phosphate 1 receptor activation reduces ischemiareperfusion injury in mouse kidney. Am. J. Physiol. 290(6): F1516-F1524. PMID:16403835

Aytac, E., Seymen, P., Dikmen, G., Uzun, H., Oktay, H. 2008. Iloprost pretreatment before unilateral nephrectomy: an experimental study in rats. Asian J. Surg. 31(2): 69-74. doi: 10.1016/S1015-9584(08)60061-5. PMID:18490218

Barrilli, A., Molinas, S., Petrini, G., Menacho, M., Elías, M.M. 2004. Losartan reverses fibrotic changes in cortical renal tissue induced by ischemia or ischemia-reperfusion without changes in renal function. Mol. Cell Biochem. 260(1-2): 161-170. PMID:15228098

Barros, P.S., Angelotti, A.C., Nobre, F., Morales, A., Fantoni, D.T., Barros, S.B. 1999. Antioxidant profile of cataractous English Cocker Spaniels. Vet. Ophthalmol. 2(2): 83-86. PMID:11397247

Basu, R.K., Wheeler, D.S. 2013. Kidney-lung cross-talk and acute kidney injury. Pediatr. Nephrol. 28(12): 2239-2248. doi: 10.1007/s00467-012-2386-3. PMID:23334385

Bolle, I., Eder, G., Takenaka, S., Ganguly, K., Karrasch, S., Zeller, C., et al. 2008. Postnatal lung function in the developing rat. J. Appl. Physiol. 104(4): 1167-1176. doi: 10.1152/japplphysiol.00587.2007. PMID:18187616

Campanholle, G., Landgraf RG, Gonc,alves, G.M., Paiva, V.N., Martins, J.O., Wang, P.H.M., et al. 2010. Lung inflammation is induced by renal ischemia and reperfusion injury as part of the systemic inflammatory syndrome. Inflamm. Res. 59(10): 861-869. doi: 10.1007/s00011-010-0198-0. PMID:20396927

Chatterjee, P.K., Patel, N.S.A., Kvale, E.O., Cuzzocrea, S., Brown, P.A.J., Stewart, K.N., et al. 2002. Inhibition of inducible nitric oxide synthase reduces renal ischemia/reperfusion injury. Kidney Int. 61(3): 862-871. PMID:11849439

Chatterjee, P.K., Patel, N.S., Sivarajah, A., Kvale, E.O., Dugo, L., Cuzzocrea, S., et al. 2003. GW274150, a potent and highly selective inhibitor of iNOS, reduces experimental renal ischemia/reperfusion injury. Kidney Int. 63(3): 853-865. PMID:12631066

Devarajan, P. 2006. Update on mechanisms of ischemic acute kidney injury. J. Am. Soc. Nephrol. 17(6): 1503-1520. PMID:16707563

Doi, K., Ishizu, T., Fujita, T., Noiri, E. 2011. Lung injury following acute kidney injury: kidney-lung crosstalk. Clin. Exp. Nephrol. 15(4): 464-470. doi: 10.1007/s10157011-0459-4. PMID:21629995

Faubel, S. 2008. Pulmonary complications after acute kidney injury. Adv. chronic 
kidney dis. 15(3): 284-296. doi: 10.1053/j.ackd.2008.04.008. PMID:18565479

Ferguson, M., Bell, C. 1988. Ultrastructural localization and characterization of sensory nerves in the rat kidney. J. Comp. Neurol. 274(1): 9-16. PMID:2458398

Hoke, T.S., Douglas, I.S., Klein, C.L., He, Z., Fang, W., Thurman, J.M., et al. 2007. Acute renal failure after bilateral nephrectomy is associated with cytokine-mediated pulmonary injury. J. Am. Soc. Nephrol. 18(1): 155-164. PMID:17167117

Joss-Moore, L.A., Wang, Y., Yu, X., Campbell, M.S., Callaway, C.W., McKnight, R.A., et al. 2011. IUGR decreases elastin mRNA expression in the developing rat lung and alters elastin content and lung compliance in the mature rat lung. Physiol. Genomics, 43(9): 499-505. doi: 10.1152/physiolgenomics.00183.2010. PMID:21363967

Kim, D.J., Park, S.H., Sheen, M.R., Jeon, U.S., Kim, S.W., Koh, E.S., et al. 2006. Comparison of experimental lung injury from acute renal failure with injury due to sepsis. Respiration, 73(6): 815-824. PMID:16960438

Klein, C.L., Hoke, T.S., Fang, W.F., Altmann, C.J., Douglas, I.S., Faubel, S. 2008. Interleukin-6 mediates lung injury following ischemic acute kidney injury or bilateral nephrectomy. Kidney Int. 74(7): 901-909. doi: 10.1038/ki.2008.314. PMID:18596724

Ko, G.J., Rabb, H., Hassoun, H.T. 2009. Kidney-lung crosstalk in the critically ill patient. Blood Purif. 28(2): 75-83. doi: 10.1159/000218087. PMID:19439927

Legrand, M., Almac, E., Mik, E.G., Johannes, T., Kandil, A., Bezemer, et al. 2009. LNIL prevents renal microvascular hypoxia and increase of renal oxygen consumption after ischemia-reperfusion in rats. Am. J. Physiol. 296(5): F1109F1117. doi: 10.1152/ajprenal.90371.2008. PMID:19225052

Ma, M.C., Huang, H.S., Wu, M.S., Chien, C.T., Chen, C.F. 2002. Impaired renal sensory responses after renal ischemia in the rat. J. Am. Soc. Nephrol. 13(7): 18721883. PMID:12089383

Meldrum, K.K., Meldrum, D.R., Meng, X., Ao, L., Harken, A.H. 2002. TNF- $\alpha-$ dependent bilateral renal injury is induced by unilateral renal ischemia-reperfusion. Am. J. Physiol. 282(2): H540-H546. PMID:11788401

Miyazawa, S., Watanabe, H., Miyaji, C., Hotta, O., Abo, T. 2002. Leukocyte accumulation and changes in extra-renal organs during renal ischemia reperfusion in mice. J. Lab. Clin. Med. 139(5): 269-78. PMID:12032487

Miranda, K.M., Espey, M.G., Wink, D.A. 2001. A rapid, simple spectrophotometric method for simultaneous detection of nitrate and nitrite. Nitric Oxide, 5(1): 62-71. PMID:11178938

Moosavi, S.M., Ashtiyani, S.C., Hosseinkhani, S. 2011. L-carnitine improves oxidative stress and suppressed energy metabolism but not renal dysfunction following release of acute unilateral ureteral obstruction in rat. Neurourol. Urodyn. 30(3): 480-487. doi: 10.1002/nau.21035. PMID:21268102

Moosavi, S.M., Ashtiyani, S.C., Hosseinkhani, S., Shirazi, M. 2010. Comparison of the effects of L-carnitine and $\alpha$-tocopherol on acute ureteral obstruction-induced renal 
oxidative imbalance and altered energy metabolism in rats. Urol. Res. 38(3): 187194. doi: 10.1007/s00240-009-0238-9. PMID:19940986

Moosavi, S.M., Bagheri, Z., Gheitasi, I., Roozbeh, J. 2013. Pre- or post-treatment with aminoguanidine attenuates a renal distal acidification defect induced by acute ureteral obstruction in rats. Can. J. Physiol. Pharmacol. 91(11): 920-928. doi: 10.1139/cjpp-2013-0059. PMID:24117259

Moosavi, S.M., Bayat, G.R., Owji, S.M., Panjehshahin, M.R. 2009: The early renal post-ischemic tissue damage and dysfunction with contribution of $\mathrm{A}_{1}$-adenosine receptor activation in rat. Nephrology, 14(2): 179-188. doi: 10.1111/j.14401797.2008.01024.x. PMID:19207864

Mount, P.F., Power, D.A. 2006. Nitric oxide in the kidney: functions and regulation of synthesis. Acta Physiol. 187(4): 433-446. PMID:16866775

Nagasu, H., Satoh, M., Kidokoro, K., Nishi, Y., Channon, K.M., Sasaki, T., et al. 2012. Endothelial dysfunction promotes the transition from compensatory renal hypertrophy to kidney injury after unilateral nephrectomy in mice. Am. J. Physiol. 302(11): F1402-F1408. doi: 10.1152/ajprenal.00459.2011. PMID:22378818

Ni, X.P., Kesterson, R.A., Sharma, S.D., Hruby, V.J., Cone, R.D., Wiedemann, E., et al. 1998. Prevention of reflex natriuresis after acute unilateral nephrectomy by melanocortin receptor antagonists. Am. J. Physiol. 274(4 Pt 2): R931-R938. PMID:9575953

Onem, Y., Ipcioglu, O.M., Haholu, A., Sen, H., Aydinoz, S., Suleymanoglu, S., et al. 2009. Posttreatment with aminoguanidine attenuates renal ischemia/reperfusion injury in rats. Ren. Fail. 31(1): 50-53. doi: 10.1080/08860220802546313. PMID:19142810

Punch, J., Rees, R., Cashmer, B., Oldham, K., Wilkins, E., Smith, D. J. Jr. 1991. Acute lung injury following reperfusion after ischemia in the hind limbs of rats. J. Trauma, 31(6): 760-767. PMID:1647465

Rabb, H., Wang, Z., Nemoto, T., Hotchkiss, J., Yokota, N., Soleimani, M. 2003. Acute renal failure leads to dysregulation of lung salt and water channels. Kidney Int. 63(2): 600-606. PMID:12631124

Rodrigo, R.N., Trujillo, S., Bosco, C. 2006. Biochemical and ultrastructural lung damage induced by rhabdomyolysis in the rat. Exp. Biol. Med. 231(8): 1430-1438. PMID:16946412

Sharfuddin, A.A., Weisbord, P.M., Palevsky, P.M., Molitoris, B.A. 2012. Acute kidney injury. In Brenner and Rector's The Kidney. Edited by M.W. Taal, G.M. Chertow, P.A. Marsden, K. Skorecki, A.S.L. Yu and B.M. Brenner. Elsevier Saunders, Philadelphia. pp. 1044-1099.

Sigmon, D.H., Gonzalez-Feldman, E., Cavasin, M.A., Potter, D.A.L., Beierwaltes, W.H. 2004. Role of Nitric Oxide in the renal haemodynamic response to unilateral nephrectomy. J. Am. Soc. Nephrol. 15(6): 1413-1420. PMID:15153552

Sutton, T.A. 2009. Alteration of microvascular permeability in acute kidney injury. Microvasc. Res. 77(1): 4-7. doi: 10.1016/j.mvr.2008.09.004. PMID:18938184 
Tokuyama, H., Kelly, D.J., Zhang, Y., Gow, R.M., Gilbert, R.E. 2007. Macrophage infiltration and cellular proliferation in the non-ischemic kidney and heart following prolonged unilateral renal ischemia. Nephron Physiol. 106(3): 54-62. PMID:17570949

Valdivielso, J.M., Pe'rez-Barriocanal, F., Garc1'a-Estan, J., Lo'pez-Novoa, J.M. 1999. Role of nitric oxide in the early renal hemodynamic response after unilateral nephrectomy. Am. J. Physiol. 276(6 Pt 2): R1718-R1723. PMID:10362752

Wongmekiat, O., Thamprasert, K., and Lumlertgul, D. 2007. Renoprotective effect of trolox against ischemia-reperfusion injury in rats. Clin. Exp. Pharmacol. Physiol. 34(8): 753-759. PMID:17600552

Zhou, J.L., Jin, G.H., Yi, Y.L., Zhang, J.L., Huang, X.L. 2003. Role of nitric oxide and peroxynitrite anion in lung injury induced by intestinal ischemia-reperfusion in rats. World J. Gastroenterol. 9(6)1318-1322. PMID:12800248 
Table 1. The levels of plasma variables before and after unilateral renal ischemia/reperfusion or unilateral nephrectomy in different groups.

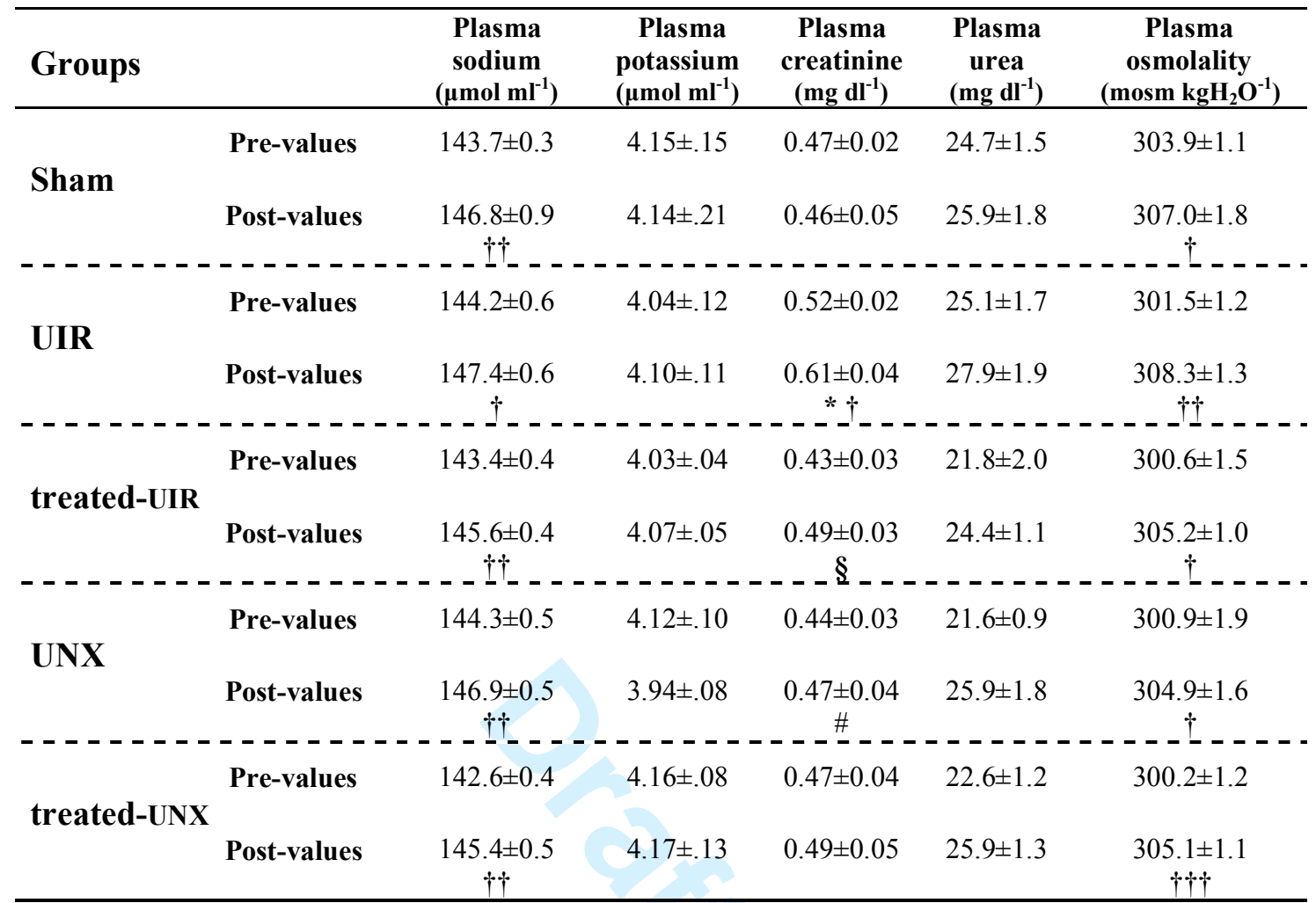

The values are expressed as means \pm SEM before (Pre-values) and $24 \mathrm{~h}$ after (Postvalues) sham-operation (sham group), a 2-h unilateral renal ischemia without treatment (UIR group) and with $\alpha$-tocopherol and aminoguanidine co-treatment (treated-UIR group), or unilateral nephrectomy without treatment (UNX group) and with $\alpha$ tocopherol and aminoguanidine co-treatment (treated-UNX group). $n=10$ in each group. ${ }^{\dagger} P<0.05,{ }^{\dagger \dagger} P<0.01,{ }^{\dagger \dagger} P<0.001$, post-value versus pre-value in each group. ${ }^{*} P<0.05$, versus the Sham group at each period. ${ }^{\S} P<0.05$, treated-UIR group versus UIR group or treated-UNX group versus UNX group at each period. ${ }^{\#} P<0.05, U N X$ group versus UIR group or treated-UNX group versus treated-UIR group at each period. 
Table 2. The levels of arterial blood variables, heart rate and weight loss following unilateral renal ischemia/reperfusion or unilateral nephrectomy in different groups.

\begin{tabular}{|c|c|c|c|c|c|c|c|}
\hline Groups & $\mathbf{p H}_{\mathrm{a}}$ & $\begin{array}{c}{\left[\mathrm{HCO}_{3}^{-}\right]_{\mathrm{a}}} \\
\left(\mu \mathrm{mol} \mathrm{mL^{-1 }}\right)\end{array}$ & $\begin{array}{l}\mathrm{P}_{\mathrm{a}} \mathrm{CO}_{2} \\
(\mathrm{mmHg})\end{array}$ & $\begin{array}{c}\mathbf{P}_{\mathrm{a}} \mathrm{O}_{2} \\
(\mathrm{mmHg})\end{array}$ & $\begin{array}{c}\text { MAP } \\
(\mathbf{m m H g})\end{array}$ & $\begin{array}{c}\text { HR } \\
\text { (beats min }{ }^{-1} \text { ) }\end{array}$ & $\begin{array}{c}\text { Body weight } \\
\operatorname{loss}(\mathrm{g})\end{array}$ \\
\hline Sham & $7.387 \pm .003$ & $23.1 \pm 0.3$ & $38.4 \pm 0.3$ & $117.5 \pm 3.9$ & $117.5 \pm 3.6$ & $395.4 \pm 10.9$ & $-14.5 \pm 2.9$ \\
\hline UIR & $7.386 \pm .003$ & $22.8 \pm 0.2$ & $37.9 \pm 0.3$ & $124.1 \pm 6.4$ & $115.0 \pm 3.0$ & $399.8 \pm 14.0$ & $-15.6 \pm 1.6$ \\
\hline treated-UIR & $7.394 \pm .004$ & $23.2 \pm 0.3$ & $37.9 \pm 0.3$ & $117.6 \pm 6.9$ & $115.0 \pm 2.2$ & $401.4 \pm 7.9$ & $-15.9 \pm 1.7$ \\
\hline UNX & $7.388 \pm .003$ & $23.7 \pm 0.3$ & $39.3 \pm 0.5$ & $116.8 \pm 4.2$ & $114.4 \pm 1.9$ & $419.6 \pm 6.6$ & $-15.1 \pm 2.5$ \\
\hline treated-UNX & $7.392 \pm .005$ & $24.0 \pm 0.6$ & $39.1 \pm 0.7$ & $107.2 \pm 7.3$ & $112.6 \pm 2.4$ & $398.1 \pm 9.1$ & $-12.2 \pm 0.9$ \\
\hline
\end{tabular}

Values are means \pm SEM for arterial $\mathrm{pH}\left(\mathrm{pH}_{\mathrm{a}}\right)$, bicarbonate concentration $\left(\left[\mathrm{HCO}_{3}{ }^{-}\right]_{\mathrm{a}}\right)$, carbon dioxide tension $\left(\mathrm{P}_{\mathrm{a}} \mathrm{CO}_{2}\right)$ and oxygen tension $\left(\mathrm{P}_{\mathrm{a}} \mathrm{O}_{2}\right)$, as well as mean arterial pressure (MAP) and heart rate (HR) during 22-24 h and body weight loss at $24 \mathrm{~h}$ after sham-operation (sham group), a 2-h unilateral renal ischemia without treatment (UIR group) and with $\alpha$ tocopherol and aminoguanidine co-treatment (treated-UIR group), or unilateral nephrectomy without treatment (UNX group) and with $\alpha$-tocopherol and aminoguanidine co-treatment (treated-UNX group). $n=10$ in each group. 
Table 3. The levels of pulmonary variables following unilateral renal ischemia/reperfusion or unilateral nephrectomy in different groups.

\begin{tabular}{|c|c|c|c|c|c|c|}
\hline Groups & $\begin{array}{c}\text { RR } \\
\left(\text { breaths } \min ^{-1}\right)\end{array}$ & $\begin{array}{c}\mathrm{AR} \\
\left(\mathrm{cmH}_{2} \mathrm{O} \mathrm{min}_{\mathrm{mL}}^{-1}\right)\end{array}$ & $\begin{array}{l}{[\operatorname{Pr}]_{\mathrm{BALF}} /[\mathrm{Pr}]_{\mathrm{P}}} \\
\quad \times 1000\end{array}$ & $\begin{array}{l}\text { Total cells in } \\
\text { BALF } \\
\left(\text { Cells } \mathrm{mm}^{-3}\right)\end{array}$ & $\begin{array}{c}{[\mathbf{E B D}]_{\text {lung }}} \\
\left(\mu \mathrm{g} \mathrm{glw}^{-1}\right)\end{array}$ & $\mathbf{P}_{\mathrm{a}} \mathbf{O}_{2} / \mathbf{F}_{\mathrm{i}} \mathbf{O}_{2}$ \\
\hline Sham & $62.8 \pm 2.0$ & $11.6 \pm 2.0$ & $25.5 \pm 0.8$ & $140.0 \pm 13.7$ & $26.1 \pm 2.4$ & $410.3 \pm 3.4$ \\
\hline UIR & $59.1 \pm 1.8$ & $14.2 \pm 1.7$ & $25.7 \pm 0.7$ & $141.0 \pm 16.1$ & $23.6 \pm 5.5$ & $375.2 \pm 3.5 * *$ \\
\hline treated-UIR & $59.2 \pm 1.0$ & $14.1 \pm 1.7$ & $25.0 \pm 0.9$ & $134.0 \pm 19.6$ & $16.8 \pm 1.6$ & $397.1 \pm 7.8 \S$ \\
\hline $\mathbf{U N X}$ & $61.8 \pm 2.3$ & $15.9 \pm 1.7$ & $25.5 \pm 0.9$ & $141.0 \pm 16.9$ & $22.0 \pm 4.1$ & $395.2 \pm 4.5 \#$ \\
\hline treated-UNX & $57.8 \pm 1.3$ & $15.0 \pm 1.7$ & $25.0 \pm 0.6$ & $120.0 \pm 25.1$ & $18.9 \pm 0.6$ & $392.4 \pm 9.1$ \\
\hline
\end{tabular}

Values are means \pm SEM for airway resistance $(n=10)$, ratio of bronchoalveolar lavage fluid (BALF) to plasma protein concentrations $\times 1000\left([\operatorname{Pr}]_{\mathrm{BALF}} /[\operatorname{Pr}]_{\mathrm{P}} \times 1000, n=5\right)$, total number of cells in BALF $(n=5)$, concentration of Evans blue dye (EBD) in lung tissue $(n=5)$, and ratio of arterial oxygen tension to inspired fraction of oxygen $\left(\mathrm{P}_{\mathrm{a}} \mathrm{O}_{2} / \mathrm{FiO}_{2}, n=10\right)$ at $24 \mathrm{~h}$ as well as respiratory rate $(n=10)$ during $22-24 \mathrm{~h}$ after sham-operation (sham group), a 2$\mathrm{h}$ unilateral renal ischemia without treatment (UIR group) and with $\alpha$-tocopherol and aminoguanidine co-treatment (treated-UIR group), or unilateral nephrectomy without treatment (UNX group) and with $\alpha$-tocopherol and aminoguanidine co-treatment (treated-UNX group). ${ }^{* *} P<0.01$ versus the Sham group. ${ }^{\S} P<0.05$ treated-UIR group versus UIR group or treated-UNX group versus UNX group. ${ }^{\#} P<0.05$ UNX group versus UIR group or treated-UNX group versus treated-UIR group. 


\section{Figure Captions}

Fig. 1. The values are expressed as means \pm SEM for plasma concentration of (A) total nitrite/nitrate $\left(\mathrm{NO}_{2}{ }^{-} / \mathrm{NO}_{3}{ }^{-}\right)$and (B) malondialdehyde (MDA) before ( $\square$ ) and $24 \mathrm{~h}$ after (घ) sham-operation (sham group), a 2-h unilateral renal ischemia without treatment (UIR group) and with $\alpha$-tocopherol and aminoguanidine co-treatment (treated-UIR group), or unilateral nephrectomy without treatment (UNX group) and with $\alpha$ tocopherol and aminoguanidine co-treatment (treated-UNX group). $n=10$ in each group. ${ }^{\dagger} P<0.05$, ${ }^{\dagger} P<0.01$ post-value versus pre-value in each group. ${ }^{*} P<0.05$, $* * * P<0.001$ versus the Sham group at each period. ${ }^{\xi} P<0.05,{ }^{\S \S} P<0.001$ treated-UIR group versus UIR group or treated-UNX group versus UNX group at each period. ${ }^{\#} P<0.05,{ }^{\# \#} P<0.01$ UNX group versus UIR group or treated-UNX group versus treated-UIR group at each period.

Fig. 2. The values are expressed as means \pm SEM in the left kidney ( $\square$ ) and the right kidney ( $\boldsymbol{\square})$ for (A) percent of kidney weight per body weight (KW/BW, $n=10)$ and (B) concentration of Evans blue dye in kidney tissue ([EBD $\left.]_{\text {kidney }}, n=5\right)$ at $24 \mathrm{~h}$, as well as (C) renal blood flow (RBF, $n=10)$ and (D) clearance of creatinine $\left(\mathrm{C}_{\mathrm{Cr}}, n=10\right)$ during a clearance period at 22-24 h after sham-operation (sham group), a 2-h unilateral renal ischemia without treatment (UIR group) and with $\alpha$-tocopherol and aminoguanidine cotreatment (treated-UIR group), or unilateral nephrectomy without treatment (UNX group) and with $\alpha$-tocopherol and aminoguanidine co-treatment (treated-UNX group).. ${ }^{\dagger} P<0.05,{ }^{\dagger \dagger} P<0.01,{ }^{\dagger \dagger} P<0.001$ right kidney versus left kidney in each group. ${ }^{*} P<0.05$, ${ }^{* *} P<0.01,{ }^{* * *} P<0.001$ versus the equivalent kidney of the sham group. ${ }^{\S \mathcal{S}} P<0.01$, ${ }^{\S \& \&} P<0.001$ equivalent kidneys of treated-UIR group versus UIR group or treated-UNX group versus $U N X$ group. ${ }^{\#} P<0.05,{ }^{\#} P<0.01$ equivalent kidneys of $U N X$ group versus UIR group or treated-UNX group versus treated-UIR group. 
Fig. 3. The values are expressed as means \pm SEM in the left kidney ( $\square$ ) and the right kidney ( $\boldsymbol{\square})$ for (A) absolute sodium excretion $\left(\mathrm{U}_{\mathrm{Na}} \mathrm{V}^{\circ}\right)$, (B) fractional sodium excretion $\left(\mathrm{FE}_{\mathrm{Na}}\right),(\mathrm{C})$ absolute potassium excretion $\left(\mathrm{U}_{\mathrm{K}} \mathrm{V}^{\circ}\right)$, (D) fractional potassium excretion $\left(\mathrm{FE}_{\mathrm{K}}\right),(\mathrm{E})$ absolute urea excretion $\left(\mathrm{U}_{\text {urea }} \mathrm{V}^{\circ}\right)$ and $(\mathrm{F})$ fractional urea excretion $\left(\mathrm{FE}_{\text {urea }}\right)$ during a clearance period at 22-24 h after sham-operation (sham group), a 2-h unilateral renal ischemia without treatment (UIR group) and with $\alpha$-tocopherol and aminoguanidine co-treatment (treated-UIR group), or unilateral nephrectomy without treatment (UNX group) and with $\alpha$-tocopherol and aminoguanidine co-treatment (treated-UNX group). $n=10$ in each group. $* P<0.05, * * P<0.01, * * * P<0.001$ versus

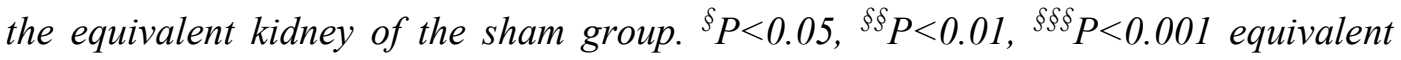
kidneys of treated-UIR group versus UIR group or treated-UNX group versus UNX group.

Fig. 4. The values are expressed as means \pm SEM in the left kidney ( $\square$ ) and the right kidney ( $\boldsymbol{\square})$ for $(\mathrm{A})$ osmolar clearance $\left(\mathrm{C}_{\mathrm{osm}}\right),(\mathrm{B})$ free-water reabsorption $\left(\mathrm{T}_{\mathrm{H} 2 \mathrm{O}}^{\mathrm{C}}\right),(\mathrm{C})$ urine flow rate $\left(\mathrm{V}^{\circ}\right)$, and $(\mathrm{D})$ urinary osmolality $\left(\mathrm{U}_{\mathrm{osm}}\right)$ during a clearance period at 22$24 \mathrm{~h}$ after sham-operation (sham group), a 2-h unilateral renal ischemia without treatment (UIR group) and with $\alpha$-tocopherol and aminoguanidine co-treatment (treated-UIR group), or unilateral nephrectomy without treatment (UNX group) and with $\alpha$-tocopherol and aminoguanidine co-treatment (treated-UNX group). $n=10$ in each group. ${ }^{*} P<0.05, * * P<0.01, * * * P<0.001$ versus the equivalent kidney of the sham group. ${ }^{\S} P<0.05,{ }^{\S} P<0.01,{ }^{\S \S \S} P<0.001$ equivalent kidneys of treated-UIR group versus UIR group or treated-UNX group versus UNX group.

Fig. 5. The values are expressed as means \pm SEM for airway pressure at sequential increasing lung volumes by $2 \mathrm{ml}$ each-times at $24 \mathrm{~h}$ after sham-operation (sham group) and (A) a 2-h unilateral renal ischemia without treatment (UIR group) and with $\alpha$ tocopherol and aminoguanidine co-treatment (treated-UIR group), or (B) unilateral nephrectomy without treatment (UNX group) and with $\alpha$-tocopherol and aminoguanidine co-treatment (treated-UNX group). $n=5$ in each group. 
Fig. 1
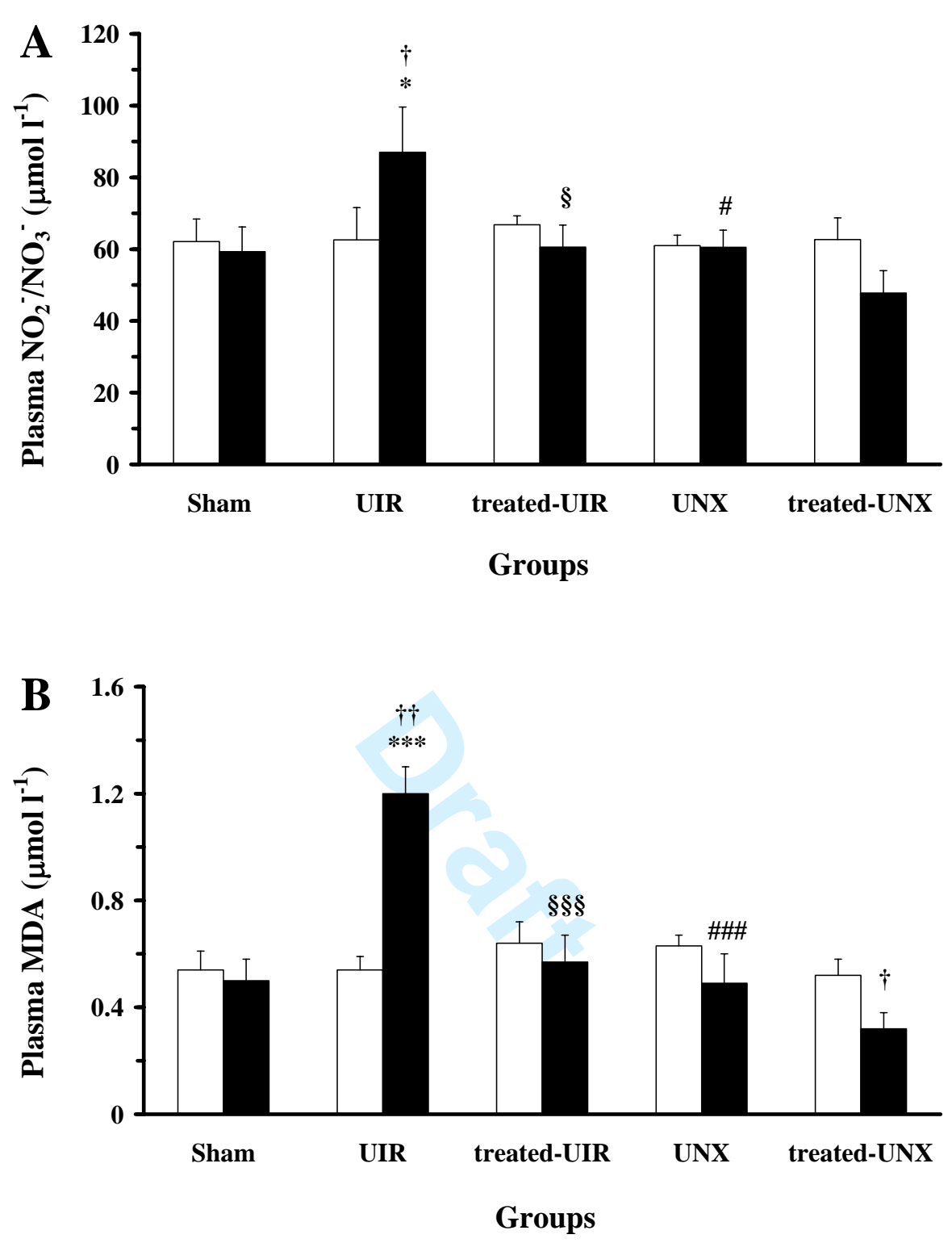
Fig. 2
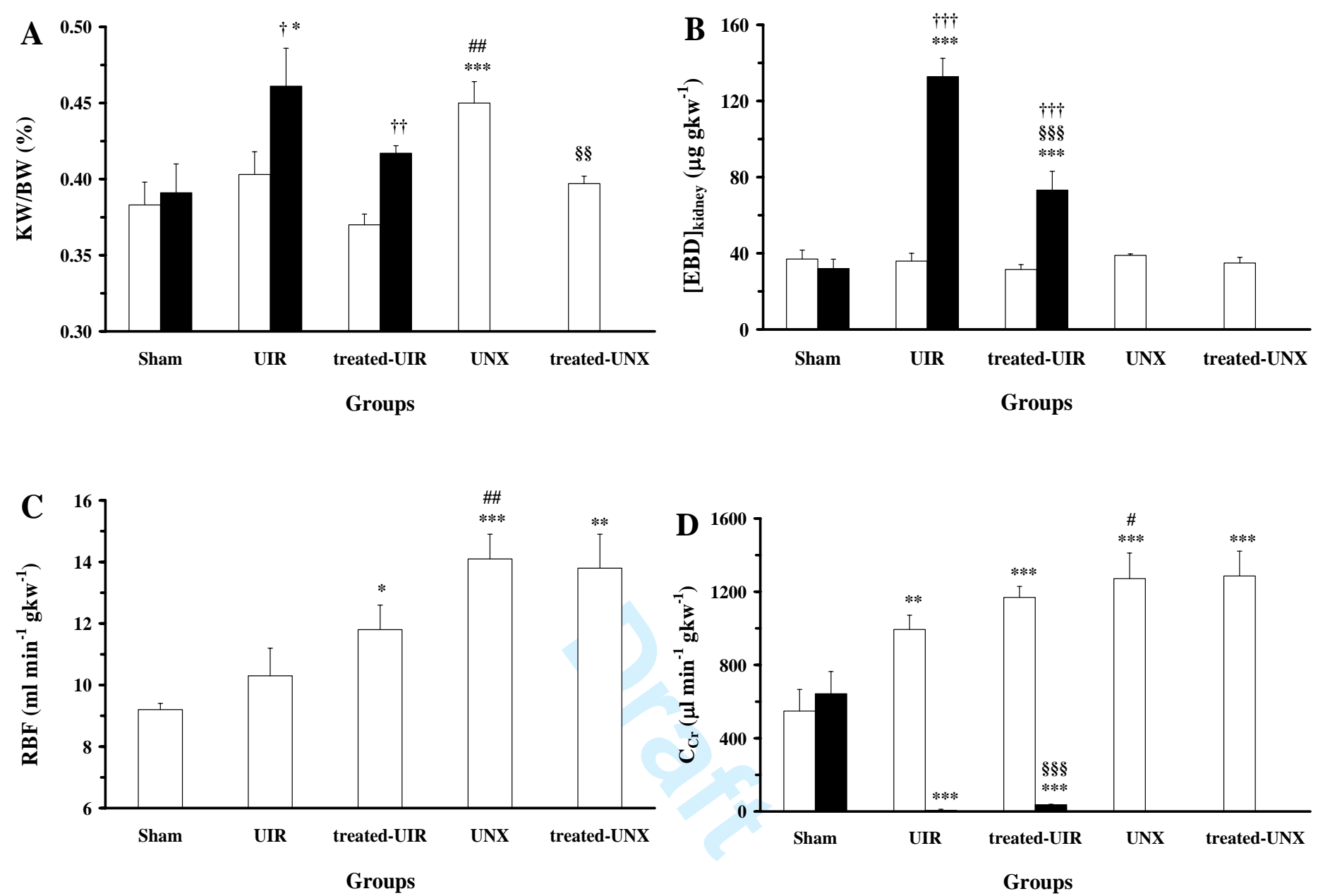
Fig. 3
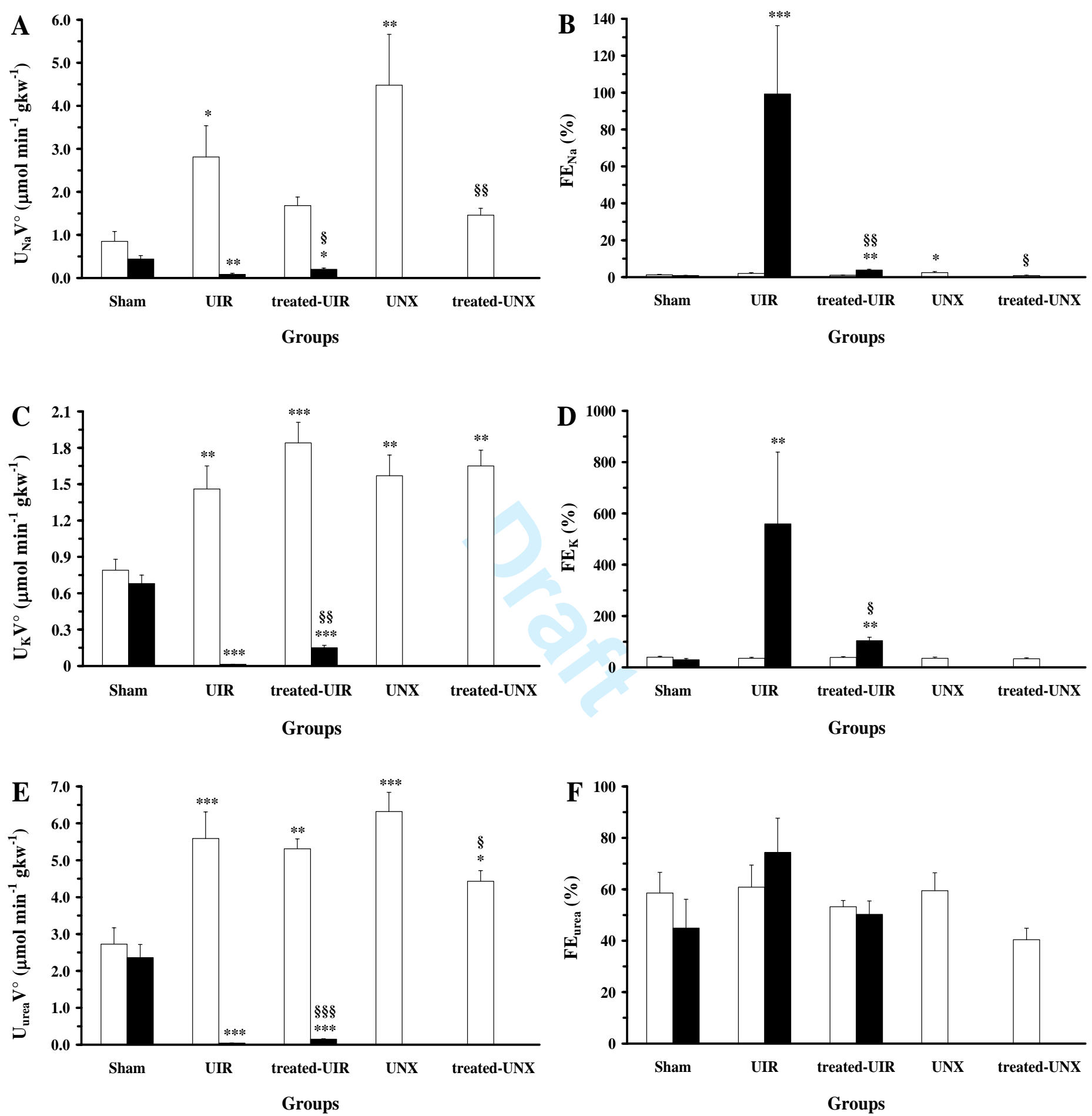


\section{Fig. 4}
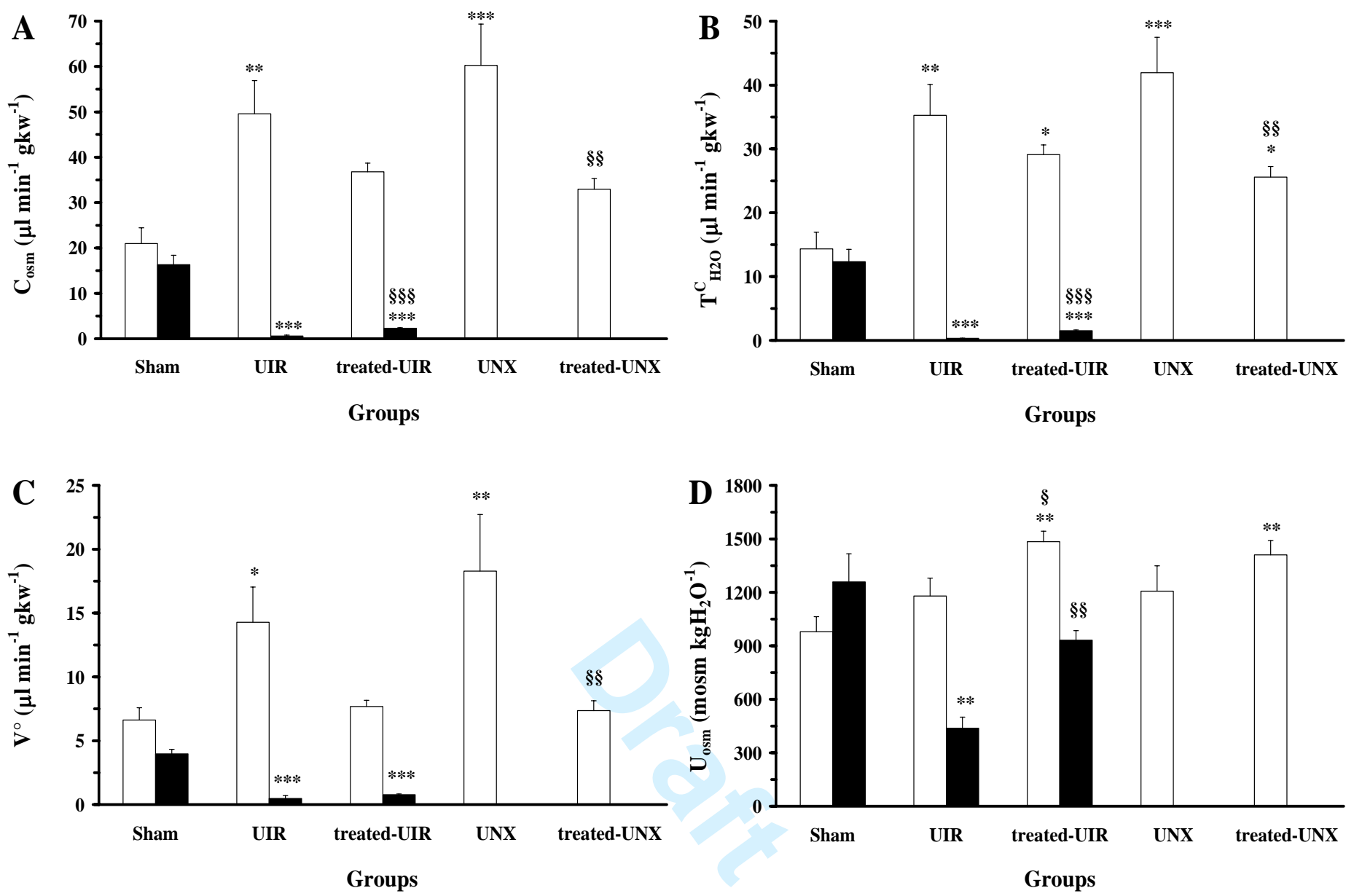
Fig. 5
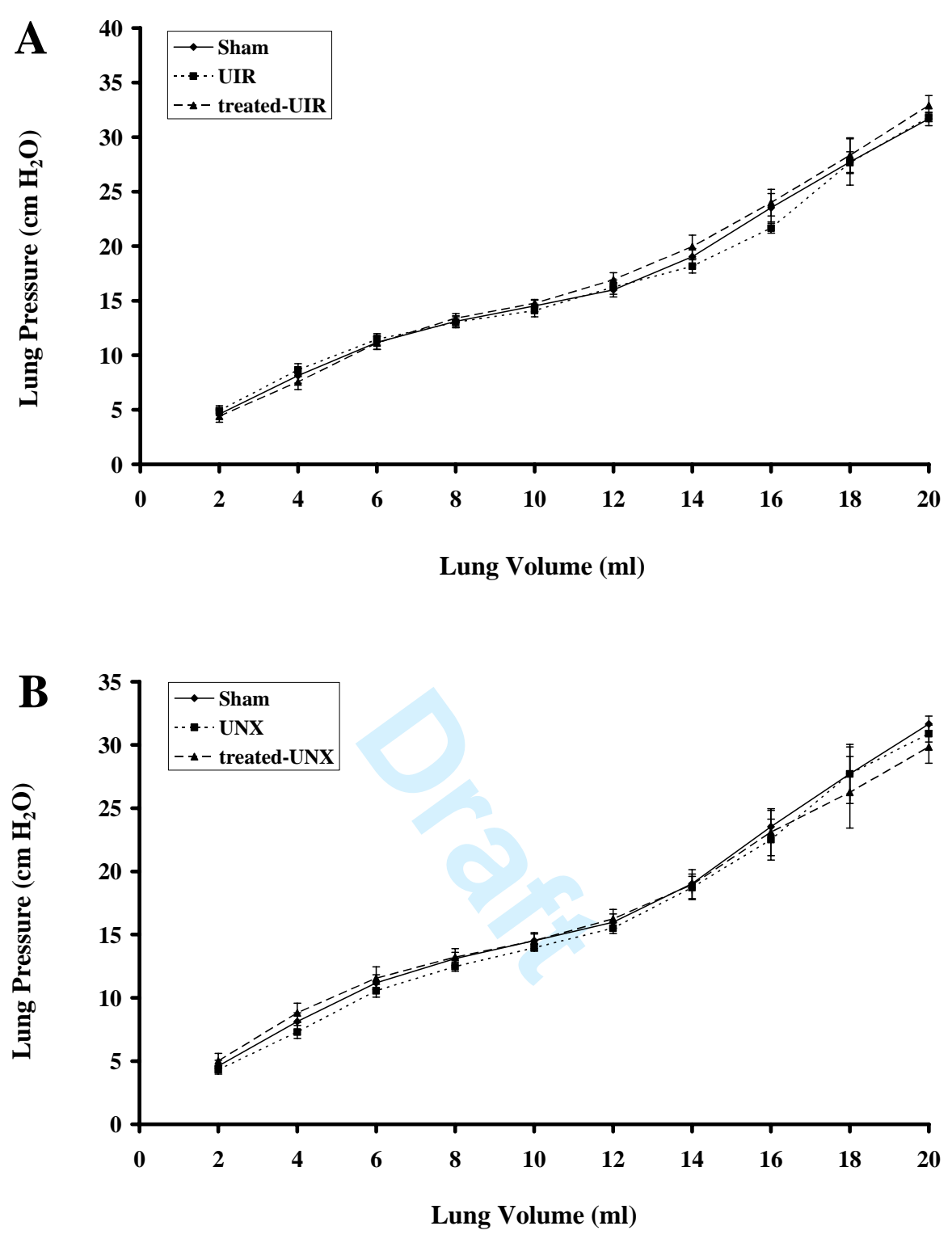